\title{
Video presentations, video conferences, seminar discourse or oral student presentation? - Are "traditional" academic genres changing or even disappearing?
}

\author{
Beatrix Kreß, Kathrin Schweiger \\ Universität Hildesheim, Universitätsplatz 1, 31141 Hildesheim, Germany
}

\begin{abstract}
The pandemic situation caused a transfer of teaching and learning into digital surroundings. This contribution shows adaptions and changes, caused by this, in different scientific communicative genres in the written and in the oral form, accompanied by shifts and modifications in the teaching and learning communication as a whole. Starting from the well-known scientific genres and forms of academic teaching and the targeted learning outcomes, coping strategies in the digital setting are described and reflected and certain consequences are pointed out. The advantages and disadvantages of this development can be discussed only after a longer-term observation, but some effects are indicated in this contribution.
\end{abstract}

\section{Introduction}

In academic communication, text genres as well as communicative genres have always served to process and to transmit knowledge. Central written and oral genres in Germanlanguage university discourse are above all the lecture, the academic lecture and, on the novice side, the student oral presentation - as well as the derivative, persecutive text genres such as the transcript/note taking, the excerpt, the thesis paper or the protocol/minutes.

The pandemic-related shift of university teaching into the virtual space also led to the introduction or increased use of so-called opencast formats, i.e. video recordings/presentation and to a focus on video conferences as a tool for synchronic teaching and learning (zoom and the like).

The questions are: what consequences will we meet through this change? Will this virtual mode of teaching lead to a change in the classic characteristics of the text genre "student oral presentation" and text genres like the i.g. transcripts/protocol/minutes. Will they disappear or does a new academic form of presentation emerge. What happens to the teaching and learning discourse, which is usually developed in the classroom? In other words, does virtual space which is now replacing the classroom - give rise to new forms of communication? Just as the Internet resulted in "new" forms of communication and text genres like weblogs etc. The possibilities and usage of tools combined with text design still have to be tried out and learned as these genres (weblog, tweeds) didn't exist before the Internet emerged. Familiar text genres - or fragments of them - are transferred to the virtual world. Over time, common practices emerge that lead to new text genres through imitation and repetition (cf. Wenz 
2014). "New media first adopt conventions of old media before developing independent formats that exploit the respective media-specific potential" (Androutsopoulos 2005:118).

\section{Student Oral Presentation}

Presentations in school or a seminar are primarily about reproducing or presenting researched facts and thoughts. Seminar papers therefore represent a genre of text that mediates between orality and written form. Presentations can be a powerful instrument of university teaching. They combine the functions of performance review, learning skills and practicing rhetorical and presentation skills. Guckelsberger (2009) specifies three central functions: a subjectrelated professionalization, a study-related qualification and a scientific and general professional qualification. 1) is a profound examination of scientific content, while 2) is the acquisition of basic research methods - not least, the (critical) processing of texts is practiced. The partial skills just mentioned are also useful for further professionalization under 3) away from the university environment. Student presentations are virtually the defining characteristic of the seminar, which for its part has dominated university teaching since the 19th century, especially in historical and linguistic studies, theology, but also in the social sciences. The University of Tübingen, for example, describes the seminar as "a course in which teachers hold discussions with students and listen to presentations together," while the University of Hanover specifies that it is a "course under the direction of one or more lecturers, to which students must contribute through their own work (e.g. papers) (Dossier Unididaktik Universität Zürich p. 2).

Traditionally, scientific conference presentations are based on formulated manuscripts, which may be read out word for word. The problem with seminar presentations, however, is their reliance on scientific reference texts, which are intended for a specific audience with an understanding of the material and are generally harder for a listening audience to understand (cf. Grzeszakowska-Pawlikowska 2020). Guckesberger (2009) identifies a central, empirically proven procedure that she calls "patchwork procedure". It says the students take over text passages from the reference texts word for word, which they put together to form a new text, i.e. the text on which the presentation is based. Apart from the fact that such a procedure approaches plagiarism, it makes - as already mentioned above - listening difficult. We assume, however, with the video recording, the patchwork procedure could find increased application - due to the need of error avoidance. Thus, the orally recorded text will also increasingly approach the (conceptual) written form. Listed below is a comparison of the basic differences between student oral presentation and video presentation.

Table 1: Presentation/Screencast

\begin{tabular}{|c|c|}
\hline Student oral presentation & Screencast \\
\hline $\begin{array}{l}\text { facial expressions and gestures support } \\
\text { understanding }\end{array}$ & no gesture and facial expression support \\
\hline syntax lexical error discontinuation of syntax & error prevention $->$ by re-recording \\
\hline $\begin{array}{l}\text { hastiness of the spoken word makes it impossible to } \\
\text { listen again }\end{array}$ & $\begin{array}{l}\text { watching again and again if one has not } \\
\text { understood something correctly. }\end{array}$ \\
\hline "feels more personal" & impersonal \\
\hline $\begin{array}{l}\text { space for intermediate questions and interaction }-> \\
\text { spontaneous }\end{array}$ & no for intermediate questions and interaction \\
\hline Pdf or Powerpoint easier for storage & $\begin{array}{l}\text { screencasts rather impractical as a storage } \\
\text { option }\end{array}$ \\
\hline
\end{tabular}

A mini survey in the course "Science Communication" in the winter semester 2020/2021 with 21 participants showed that - when it comes to creating a presentation themselves - half of the participants favor an oral presentation and the other half prefers a video recording. 
From the recipient's perspective, as a listener, there is a preference for the screencast version: 59 percent prefer the "preserved" form of presentation.

\section{The transcription/note taking}

Taking notes, and with it the transcript, is one of the central text productions in the university. Taking notes has above all a memory-supporting function and serves as a basis for further processing, for example, for the protocol or for exam preparation. Steets (2003) speaks of a text genre without specification, because in fact it is not an "official" standardized text genre, there are no formalities for it. A successful transcript makes it possible to visualize the contents of the presentation. How comprehensive or how "objective" the transcript is depends to a large extent on the prior knowledge of the person taking notes.

Another mini survey in the course "Science Communication" in the winter semester 2020/2021 with 21 participants revealed that a small majority of participants take notes by hand (53 percent), while 47 percent type the notes right away on their devices. 67 percent of participants say they have taken fewer notes since the online teaching transition. One reason why there is now a tendency for less note-taking: If a device is used to play the presentation and to take notes at the same time, this makes it more difficult to take notes, i.e. if typing is preferred. Seminar participants further mentioned that lecturers now make use of the online "note taking" tool - which functions similarly to a whiteboard - and then make these available as screenshots. Otherwise, it can also be assumed that students photograph presentations in front of the screen.

\section{Teaching and learning discourse}

Questionnaires, surveys, informal discussions show: students and lecturers alike miss direct communication in digital learning, despite the fact that most universities established different videoconferencing technologies to allow synchronic and direct communicative exchange. However, due to technical reasons and out of social shyness in the new surrounding, communication as a dialogical exchange rarely develops.

Especially teachers expect from the direct exchange in the classroom, the teaching and learning discourse, certain outcomes. Coming from a taxonomy of skills and learning progression (cf. Anderson et al., 2001, p. 27), remember, understand, apply, analyze, evaluate and finally create, classroom discourse is expected to foster all of them. Knowledge is shared through discourse, understanding can be ensured by communication in question-answerschemes, and by guided debates higher ordered analytical and critical competences should be facilitated. Linguists emphasize desirable side effects: Communication skills, the ability to use terminology and the scientific register appropriately, to express difficult processes and connections, but also to formulate an opinion or evaluation and be capable to argue it. An acceleration of knowledge and the creation of new insights is expected through that (cf. Lemke 1990: 87-124; Redder 2014, p. 32-33; Ehlich, 2014, p. 45-48). As the scientific debate - and hence the classroom discourse as a discussion in the scientific community "in miniature" - is shaped by controversy (in a productive way), students also acquire social skills: How is opposition stated without being too offensive, but still clear? How can a strong deviation be mitigated?

In order to save some of the advantages of classroom discourse, such as the linguistic examination of theoretical content in order to practice terms and scientific expression, and to promote the higher leveled learning outcomes, some aims are relocated into the written medium, which sounds somehow like contradiction to what is said before. However, the dialogue in video conferences seems to be so loaded from the technical and as well from the 
psychological side, especially in larger groups, that only rather simple interactions, such as inquiries, questions and answers in chats etc., were feasible.

So, theoretical discussions, the deepened work with theoretical texts and the practical and analytical implementation were shifted in the written medium. The tasks for writing were then modelled in a way to preserve some of the discursive benefits. This was realized by impulses that allowed personal involvement. The importance of applicability of knowledge and learning outcomes and their embedding in everyday life is commonplace, and it became even more important through the remote situation in digital learning. The material and the task should also be able to encourage some kind of interior dialogue, a discourse with oneself, so different viewpoints and their argumentation were possible. Finally, however, it was also important that the challenge did not resemble well-known exam formats such as term papers or the like. The skills that are to be developed through these types of examinations are embedded to a sufficient extent in the current study programs and promote other competencies such as a critical review of the state of research, developing and arguing an own research focus or research question and writing a longer academic text in a structured and appropriate way. A duplication would have caused frustration.

In the new established written tasks, the focal point is different. It is on multiperspectivity, argumentation and a "dialogue" of these different point of views with each other, so that not one thread is argued through a longer text, but the skills, promoted by a fruitful debate. Tasks that foster this have to start in rather precise and tangible setting. It should allow a question like "how I would feel in this situation?", i.e. a quite egocentric point of view, which is followed by the need to change perspectives, as a transfer to an idiosyncratic starting point necessitates alterations and adjustments. This way, a somehow new genre is created that might be characterized as "somewhere in between personal journal/diary and scientific essay".

\section{Conclusion}

Of course, it is premature and no representative surveys are yet available to confirm whether traditional text and discourse genres are changed, adapted, or no longer used at all. Herring (2013) speaks of adapted (reconfigured) communicative practices in web 2.0 (personal status updates, quoting/re-tweeting, blogging) and new phenomena (collaborative and especially multimodal practices of various kinds), which can be regarded as fields of investigation of pragmatics. Transferred to text genres, student presentations - mediated by the screencast might be seen as a kind of adapted text genre. Some types of communication - e. g. the classroom dialogue - seem to be nontransferable, in any case one-to-one, so a media change might be useful. This leads to new text genres. So, many changes can be observed and documented and the situation after the pandemic is not the same also in this way. The advantages and disadvantages are not yet fully foreseeable and should also be discussed.

\section{References}

1. L. W. Anderson et al., A taxonomy for learning, teaching and assessing: a revision of bloom's taxonomy of educational objectives. New York: Longman (2001)

2. J. Androutsopoulos, Online-Magazine \& Co: Publizistische Nischenangebote im Internet. In: Siever, Torsten / Peter Schlobinski / Jens Runkehl (ed.) Websprache.net, 98131. Berlin: de Gruyter (2005)

3. K. Ehlich, Argumentieren als sprachliche Ressource des diskursiven Lernens. In: Hornung, A., Carrobio, G., Sorrentino, D. Diskursive und textuelle Strukturen in der 
Hochschuldidaktik: Deutsch und Italienisch im Vergleich. Münster: Waxmann. 41 (2014)

4. Universität Zürich Arbeitsstelle für Hochschuldidaktik AfH Dossier Unididaktik 1/06 https://www.weiterbildung.uzh.ch/dam/jcr:00000000-1937-95a7-0000-

$000065 \mathrm{e} 498 \mathrm{ec} / \mathrm{Du}$ _Studentische_Referate.pdf. Retrieved 17.12.2020

5. S. Guckelsberger, Mündliche Referate in der Universität: linguistische Einblicke, didaktische Ausblicke. In: Meer, Dorothee/ Lévy-Tödter (Hrsg.) Hochschulkommunikation in der Diskussion. Lang: Frankfurt a. M., 71 (2009)

6. B. Grzeszakowska-Pawlikowska, Rhetorische Kompetenzen in der Fremdsprache Deutsch (DaF). Wirkung und Verständlichkeit polnischer Studentinnen in der interkulturellen Hochschulkommunikation $[=$ Schriften zur Sprechwissenschaft und Phonetik 19.] Berlin: Frank\&Timme (2020)

7. S. C. Herring, Discourse in Web 2.0: Familiar, reconfigured, and emergent. In D. Tannen \& A. M. Tester (Eds.), Georgetown University Round Table on Languages and Linguistics 2011: Discourse 2.0: Language and new media (pp. 1-25). Washington, DC: Georgetown University Press. Prepublication version: http://ella.slis.indiana.edu/ herring/GURT.2011.prepub.pdf. Retrieved 17.12.2020 (2013)

8. J. L. Lemke, Talking science: Language, learning, and values. Norwood, NJ: Greenwood (1990)

A. Redder Wissenschaftssprache - Bildungssprache - Lehr-Lerndiskurs. In: Hornung, A., Carrobio, G., Sorrentino, D. Diskursive und textuelle Strukturen in der Hochschuldidaktik: Deutsch und Italienisch im Vergleich. Münster: Waxmann. 25 (2014)

A. Steets, Die Mitschrift als universitäre Textart - Schwieriger als gedacht, wichtiger als vermutet. In: Ehlich, K.; Steets, A. (ed.) Wissenschaftlich schreiben - lehren und lernen. de Gruyter: Berlin, New York, 51 (2003)

9. K. Wenz, Entstehung neuer Textsorten im Internet - Überlegungen am Beispiel von Weblogs. Retrieved on 17.12.2020. http://opus.bsz-bw.de/ubhi/volltexte/2014/241 (2014) 